\title{
Land surface temperature representativeness in a heterogeneous area through a distributed energy-water balance model and remote sensing data
}

\author{
C. Corbari ${ }^{1}$, J. A. Sobrino ${ }^{2}$, M. Mancini ${ }^{1}$, and V. Hidalgo ${ }^{2}$ \\ ${ }^{1}$ Department of Hydraulic, Environmental and Surveying Engineering, Politecnico di Milano, Milan, Italy \\ ${ }^{2}$ Global Change Unit, Image Processing Laboratory, Universitat de Valencia, Valencia, Spain
}

Received: 19 July 2010 - Published in Hydrol. Earth Syst. Sci. Discuss.: 4 August 2010

Revised: 21 October 2010 - Accepted: 26 October 2010 - Published: 29 October 2010

\begin{abstract}
Land surface temperature is the link between soilvegetation-atmosphere fluxes and soil water content through the energy water balance. This paper analyses the representativeness of land surface temperature (LST) for a distributed hydrological water balance model (FEST-EWB) using LST from AHS (airborne hyperspectral scanner), with a spatial resolution between 2-4 m, LST from MODIS, with a spatial resolution of $1000 \mathrm{~m}$, and thermal infrared radiometric ground measurements that are compared with the representative equilibrium temperature that closes the energy balance equation in the distributed hydrological model.

Diurnal and nocturnal images are analyzed due to the non stable behaviour of the thermodynamic temperature and to the non linear effects induced by spatial heterogeneity.

Spatial autocorrelation and scale of fluctuation of land surface temperature from FEST-EWB and AHS are analysed at different aggregation areas to better understand the scale of representativeness of land surface temperature in a hydrological process.

The study site is the agricultural area of Barrax (Spain) that is a heterogeneous area with a patchwork of irrigated and non irrigated vegetated fields and bare soil. The used data set was collected during a field campaign from 10 to 15 July 2005 in the framework of the SEN2FLEX project.
\end{abstract}

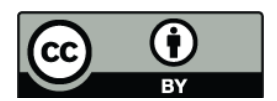

Correspondence to: C. Corbari (chiara.corbari@mail.polimi.it)

\section{Introduction}

The importance of the spatial resolution problem in hydrological modelling has been highlighted in the scientific community since 1980s (Dooge, 1986; Sivapalan and Wood, 1986; Wood et al., 1988; Wood, 1994; Blöschl and Sivaplan, 1995; Wood, 1998; Su et al., 1999).

In particular the development of distributed hydrologic models (Noihlan and Planton, 1989; Famiglietti e Wood, 1994; Rabuffetti et al., 2008; Ravazzani et al., 2008; Troch et al.,1993; Montaldo et al., 2007; Gurtz et al., 2002) gave the opportunity to better understand this problem of spatial scale of the hydrological variables (Anderson et al., 2004; McCabe and Wood, 2006; Kustas et al., 2004) due to the fact that a distributed model predicts averaged variable values in each pixel.

Moreover the recent advances in remote sensing technologies drove the scientific community to the use of hydrologic modelling in conjunction with remote sensing data. So there was a development of hydrological models for water content estimation from mass and energy balance (Noilhan and Planton, 1989; Famiglietti and Wood, 1994; Bastiaanssen et al., 1998; Montaldo and Albertson, 2001; Anderson et al., 2004; Corbari et al., 2008; Corbari, 2010; Su, 2002; Mincapilli et al., 2009) and remote sensing data through connected variables to soil moisture such as land surface temperature (LST). This approach seems to solve many limitations and difficulties of the previous technology based on microwave satellite images (Mancini et al., 1999; Giacomelli et al., 1995). In fact, promising results are now coming using both hydrological modelling and thermal infrared images available from operative satellite sensors like MODIS, AVHRR, ASTER and SEVIRI.

Published by Copernicus Publications on behalf of the European Geosciences Union. 
However there are still problems of understanding the spatial variability of satellite images and its effect on the hydrological variables (Su et al., 1999; Kustas et al., 2004).

In fact the problems related to the retrieval of satellite LST over heterogeneous areas are still open issues in the research community due to the fact that land surface temperature is a function of the brightness temperature and emissivity of each component of the area (bare soil or vegetation), of the scan angle of view of the radiometer and of the spectral resolution of the sensor (Norman et al., 1995; Soria and Sobrino, 2007; Jiménez-Muñoz and Sobrino, 2007).

So thermal infrared ground measurements allow a control and a local verification of algorithms implemented into hydrologic models and of the products distributed by different spatial agencies (Sobrino et al., 1994; Schmugge et al., 1998) even if there are still difficulties in the comparison between ground and areal measurements.

This paper analyses the representativeness of land surface temperature for a distributed hydrological water balance model (FEST-EWB: Flash-flood Event-based Spatiallydistributed rainfall-runoff Transformation-Energy Water Balance) using data at different spatial resolution. LST from AHS (airborne hyperspectral scanner), with a spatial resolution between 2-4 m, LST from MODIS, with a spatial resolution of $1000 \mathrm{~m}$, and thermal infrared radiometric ground measurements are compared with the land surface temperature from the hydrological model.

The spatial autocorrelation function (Rodriguez-Iturbe et al., 1995) is also analysed to understand the effect of the aggregation process on land surface temperature statistical parameters and, also from the analysis of the scale of fluctuation (VanMarcke, 1983), to understand at which aggregation area LST variance becomes insignificant for the process. In fact, if a process at high aggregation area is considered, the variance tends to zero while the scale of fluctuation is higher and these concepts can also be related to the hydrological modelling observing that a lumped model has obviously a bigger level of indetermination than a distributed model.

The distributed energy water balance model, FEST-EWB, looks for the representative thermodynamic equilibrium temperature that is the land surface temperature that closes the energy budget (Corbari et al., 2008; Corbari, 2010). The model is validated at field scale with fluxes measured from an eddy correlation tower and with measured land surface temperature.

The study site is the agricultural area of Barrax (Spain) that is a heterogeneous area with a patchwork of irrigated and non irrigated vegetated fields and bare soil. The used data set was collected during a field campaign from 10 to 15 July 2005 in the framework of the SEN2FLEX (SENtinel-2 and FLuorescence EXperiment) project funded by ESA (SEN2FLEX Final Report, 2006; Sobrino et al., 2008; Su et al., 2008).

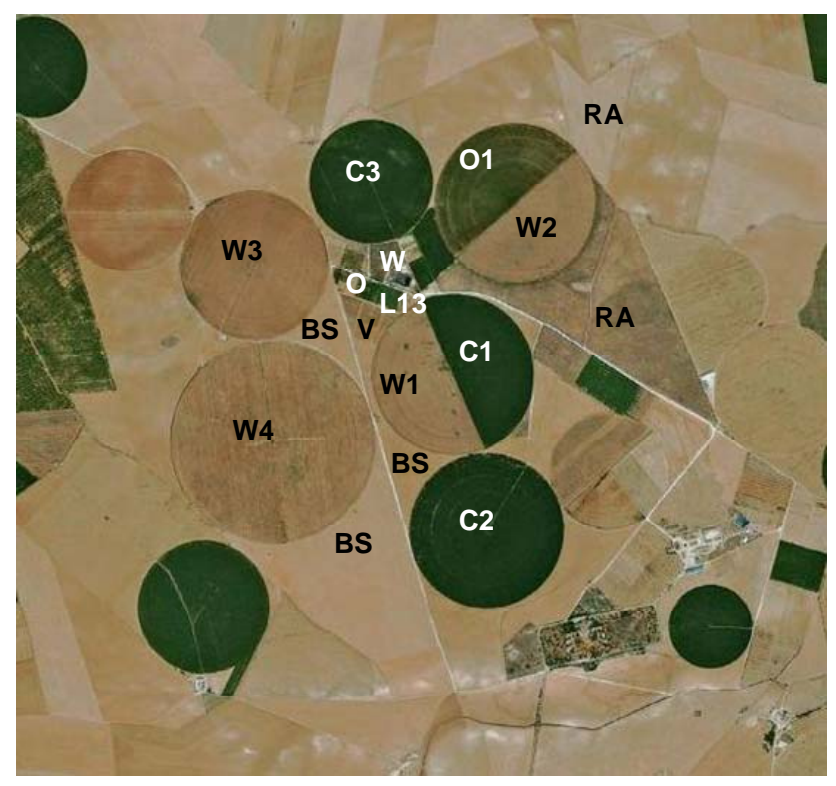

Fig. 1. Study area and fields codes.

\section{Data}

\subsection{The study site}

The test site is located in the agricultural area of Barrax $\left(39^{\circ} 3^{\prime} \mathrm{N}, 2^{\circ} 6^{\prime} \mathrm{W}, 700 \mathrm{~m}\right.$ a.s.l) near Albacete in Spain. This area is characterized by a patchwork of irrigated and non irrigated fields with different shape and size where about $65 \%$ of cultivated lands are dryland $(67 \%$ winter cereals, $33 \%$ fallow) and 35\% irrigated land (75\% corn, $15 \%$ barley/sunflower, $5 \%$ alfalfa, $5 \%$ onions and other vegetables). This area was selected as a test site for a field campaign during June-July 2005 in the framework of the international project SEN2FLEX. In Fig. 1 a map of the study area is presented with the plots where ground measurements are performed. This area has a Mediterranean climate with dry summer and high temperatures. Distributed soil moisture measurements were made during the field campaign in the different type of vegetated fields and bare soil by University of Naples (SEN2FLEX Final Report, 2006) and these values are used as initial condition for the modeling simulation.

\subsection{Land surface temperature retrieved from AHS}

During the field campaign 12 day and night overpasses of the airplane with on board AHS were performed and images with different spatial scale resolutions $(2 \mathrm{~m}$ and $3 \mathrm{~m}$ ) have been collected (Table 1). Land surface temperature values are obtained with TES method (Gillespie et al., 1998) and these results are reported in (Sobrino et al., 2008).

This heterogeneous agricultural area can be characterized from a thermodynamic point of view only with high resolution images. In fact the alternation between wet and dry areas 
Table 1. LST computed from AHS images.

\begin{tabular}{lrllcrr}
\hline $\begin{array}{l}\text { Date } \\
\text { (yymmdd) }\end{array}$ & Time & $\begin{array}{l}\text { Flight } \\
\text { ID }\end{array}$ & $\begin{array}{l}\text { Altitude } \\
(\mathrm{m} \text { a.s.1. })\end{array}$ & $\begin{array}{r}\text { Pixel size } \\
(\mathrm{m})\end{array}$ & $\begin{array}{r}\text { Mean LST } \\
\left({ }^{\circ} \mathrm{C}\right)\end{array}$ & $\begin{array}{r}\text { Standard } \\
\text { deviation } \\
\text { LST }\left({ }^{\circ} \mathrm{C}\right)\end{array}$ \\
\hline 050712 & $13: 56$ & BDS & 1675 & 2 & 48 & 9.5 \\
050712 & $14: 21$ & MDS & 2070 & 3 & 49.4 & 9.7 \\
050712 & $00: 07$ & BNS & 1675 & 2 & 21.8 & 1.5 \\
050712 & $00: 32$ & MNS & 2070 & 3 & 21.3 & 1.3 \\
050713 & $9: 52$ & B1S & 1675 & 2 & 28.6 & 3.4 \\
050713 & $10: 15$ & M1S & 2070 & 3 & 31 & 4 \\
050713 & $13: 46$ & B2S & 1675 & 2 & 48 & 9.7 \\
050713 & $14: 01$ & M2S & 2070 & 3 & 48.6 & 9.6 \\
050714 & $10: 03$ & B1S & 1675 & 2 & 29.8 & 3.4 \\
050714 & $10: 23$ & M1S & 2070 & 3 & 31.9 & 4 \\
050714 & $14: 06$ & B2S & 1675 & 2 & 44 & 7.4 \\
050714 & $14: 25$ & M2S & 2070 & 3 & 44.2 & 7.3 \\
\hline
\end{tabular}

is clearly visible during the day, when standard deviation of LST can reach very high values till $9.7^{\circ} \mathrm{C}$, while during the night the area seems to be homogeneous with a maximum standard deviation of $1.3{ }^{\circ} \mathrm{C}$ (Table 1$)$.

\subsection{MODIS images}

LST products from MODIS radiometer on board of TERRA satellite (http://ladsweb.nascom.nasa.gov/index.html), with a spatial resolution of $1 \mathrm{Km}$, are used in this study to understand the ability of low resolution images from operative satellite to reproduce land surface temperature variability. A nighttime image for 13 July at 00:10 and a daytime image for 13 July at 13:45 were selected.

\subsection{Thermal radiometric field campaign}

Thermal radiometric ground measurements were collected by UGC - Universitad de Valencia during the airplane overpasses, during night and day, over corn (as $\mathrm{C} 1$ field), bare soil (BS), green grass (L13), water body (WB), wheat (as $\mathrm{W} 1$ field), vineyard $(\mathrm{V})$, onion $(\mathrm{O})$ and area of reforestation (RA) (Fig. 1). Various instruments were used to measure in the TIR domain, including multiband and single-band radiometers with a fixed field-of-view (Sobrino et al., 2008).

\subsection{Micrometeorological stations}

An eddy correlation tower in the vineyard field (V) measured the turbulent fluxes of sensible and latent heat and $\mathrm{CO}_{2}$ fluxes above the canopy through the covariance between the vertical wind velocity and respectively the air temperature, the water vapour density and $\mathrm{CO}_{2}$ density. Moreover relative humidity, air temperature, soil heat flux, soil temperature and the four component radiation were measured. The systems were installed at $410 \mathrm{~cm}$ height. The used energy fluxes were col- lected from 10 July to 15 July 2005 from the Faculty of GeoInformation Science and Earth Observation of the University of Twente (SEN2FLEX Final Report, 2006; Su et al., 2008). Moreover the University of Castilla-La Mancha operated three agro-meteorological stations in the area providing meteorological information (SEN2FLEX Final Report, 2006).

\section{Hydrological model: FEST-EWB}

FEST-EWB (Flash-flood Event-based Spatially-distributed rainfall-runoff Transformation-Energy Water Balance) is a distributed hydrological energy water balance model (Corbari et al., 2008; Corbari et al., 2010) and it is developed starting from the FEST-WB and the event based models FEST98 and FEST04 (Mancini, 1990; Rabuffetti et al., 2008; Ravazzani et al., 2008). FEST-EWB computes the main processes of the hydrological cycle in every cells: evapotranspiration, infiltration, surface runoff, flow routing, subsurface flow and snow dynamic (Corbari et al., 2009). The energy balance is solved looking for the representative thermodynamic equilibrium temperature (RET) defined as the land surface temperature that closes the energy balance equation. So using this approach, soil moisture is linked to latent heat flux and then to LST. RET thermodynamic approach solves most of the problems of the actual evapotranspiration and soil moisture computation. In fact it permits to avoid computing the effective evapotranspiration as an empirical fraction of the potential one.

The complete energy balance equation at the ground surface in FEST-EWB is expressed as:

$R_{\mathrm{n}}-G-\left(H_{\mathrm{s}}+H_{\mathrm{c}}\right)-\left(L E_{\mathrm{s}}+L E_{\mathrm{c}}\right)=F_{\mathrm{CO} 2}+S_{\mathrm{c}}+S_{\mathrm{air}}+S_{\mathrm{s}}$

where: $\mathrm{R}_{\mathrm{n}}\left(\mathrm{Wm}^{-2}\right)$ is the net radiation, $G\left(\mathrm{Wm}^{-2}\right)$ is the soil heat flux, $H_{\mathrm{s}}$ and $H_{\mathrm{c}}\left(\mathrm{Wm}^{-2}\right)$ and $L E_{\mathrm{s}}$ and $L E_{\mathrm{c}}\left(\mathrm{Wm}^{-2}\right)$ 

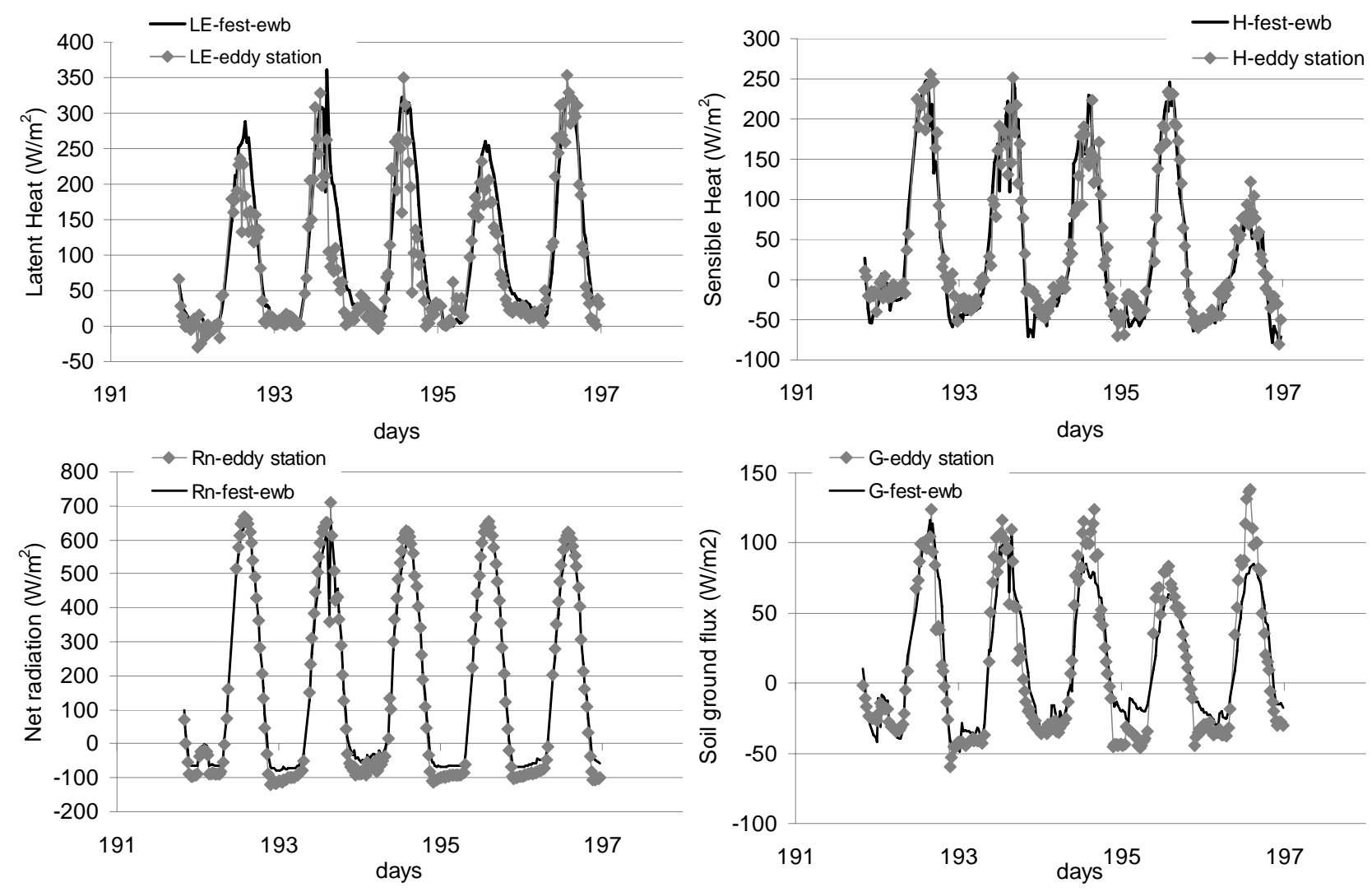

Fig. 2. Comparison between simulated and measured energy fluxes.

are respectively the sensible heat and latent heat fluxes for bare soil (s) and for canopy (c) and the energy storage terms: the photosynthesis flux $\left(F_{\mathrm{CO} 2}\right)$, the crop and air enthalpy changes ( $S_{\text {canopy }}$ and $S_{\text {air }}$ ) and the soil surface layer heat flux $\left(S_{\mathrm{s}}\right)\left(\mathrm{Wm}^{-2}\right)$. These terms are often negligible, especially at basin scale with a low spatial resolution; instead at local scale the contribution of these terms could be significant (Corbari et al., 2010; Meyers and Hollinger, 2004).

FEST-EWB model is run at two different spatial resolutions, of $10 \mathrm{~m}$ and of $1000 \mathrm{~m}$, for the comparison with airborne and satellite data.

\section{Energy water balance model validation}

\subsection{Comparison with energy fluxes from eddy covariance station}

The closure of energy budget with fluxes measured at the eddy covariance station is checked to evaluate the goodness of measured ground data and the implication that has on the interpretation of energy fluxes (Wilson et al., 2002; Corbari, 2010). The closure of the energy balance with raw data shows a linear regression forced through the origin equal to $y=0.773 x$ with $R^{2}=0.946$ (SEN2FLEX Final Report, 2006; Su et al., 2008). Only daytime data are used for this comparison due to problems in turbulent fluxes retrieval during stable atmospheric conditions which are typical of night (Wilson et al., 2002). Measured net radiation, latent and sensible heat fluxes and soil heat flux are then compared with simulated fluxes from FEST-EWB simulation at $10 \mathrm{~m}$ spatial resolution and a good accuracy is reached showing high values of the slope of the linear regressions between measured and simulated fluxes (Fig. 2).

The goodness of these results is also confirmed from a statistical analysis looking for the minimization of the root mean square error and the maximization of the efficiency of the Nash and Sutcliffe index (Nash and Sutcliffe, 1970). Net radiation is the flux with the highest efficiency, $\eta$ equal to 0.99 , and the lowest RMSE, equal to $30 \mathrm{~W} / \mathrm{m}^{2}$; instead the latent heat flux has the lowest $\eta$ equal to 0.78 and the highest RMSE equal to $44.4 \mathrm{~W} / \mathrm{m}^{2}$ (Table 2).

\subsection{Comparison with LST from AHS airborne radiometer}

RETs from FEST-EWB are selected for the same instant of LSTs AHS images, which have been resampled at the same spatial resolution of FEST-EWB images, equal to $10 \mathrm{~m}$. In Table 3 mean, standard deviation and RMSE of the differences between LSTs from AHS and simulated RETs are 
Table 2. Nash and Sutcliffe index and RMSE for the energy fluxes.

\begin{tabular}{lll}
\hline & $\eta$ & RMSE $\left(\mathrm{Wm}^{-2}\right)$ \\
\hline Net Radiation & 0.99 & 30 \\
Latent Heat & 0.78 & 44.4 \\
Sensible Heat & 0.89 & 27.8 \\
Ground Heat & 0.88 & 17.9 \\
\hline
\end{tabular}

reported showing a good behaviour of the model in representing observed data. In particular, at this fine resolution, the model as well as the AHS is capable in representing the heterogeneity of the area that is strictly linked to vegetation type, growth vegetation period and irrigation. The mean difference between RET minus LST from AHS has its maximum value during the night and is equal to $-1.24^{\circ} \mathrm{C}$ with a standard deviation of $0.73^{\circ} \mathrm{C}$ and a rout mean square error of $3.36^{\circ} \mathrm{C}$. If all 12 images are considered the total mean of the mean differences of LSTs is equal to $-0.33^{\circ} \mathrm{C}$ with a standard deviation of $1.26^{\circ} \mathrm{C}$; but when the daytime values are compared, a mean value of $-0.15^{\circ} \mathrm{C}$ is reached.

\subsection{Comparison with LST from ground radiometers}

Daytime thermal infrared radiometric ground measurements are compared with land surface temperature retrieved from AHS and with simulated RET for different types of crops. Considering all the data set, good results are found (Fig. 3) with low values of $R^{2}$ and of the slope of the linear regression between the different temperatures. In fact the mean difference between RET and in situ measurements is equal to $-1{ }^{\circ} \mathrm{C}$ with a standard deviation of $1.9^{\circ} \mathrm{C}$ and RMSE of $2.1^{\circ} \mathrm{C}$. If in situ measurements and LST from AHS are compared, the mean difference is equal to $0.9^{\circ} \mathrm{C}$, (standard deviation $=2.1{ }^{\circ} \mathrm{C}$ and $\mathrm{RMSE}=2.3^{\circ} \mathrm{C}$ ). Good results are also found comparing RET and LST from AHS with a mean difference of $-0.2{ }^{\circ} \mathrm{C}$ and a standard deviation of $1.2^{\circ} \mathrm{C}$ and $\mathrm{RMSE}=1.2^{\circ} \mathrm{C}$.

\section{Effect of the scale of resolution on LST spatial variability}

Usually the finer the spatial scale of LST information is, the more accurate the estimate of energy and water fluxes will be. In this article the effect of the scale of resolution on LST spatial variability is studied. In particular LST maps from AHS and from MODIS and RET from FEST-EWB are compared for two different dates, during daytime and nighttime, to understand the effect of scale resolution on land surface temperature variability. Spatial resolution at increasing scale offers the possibility to understand the ability of MODIS resolution to represent land surface temperature over extremely heterogeneous area (Kustas et al., 2004; McCabe and Wood, 2006).
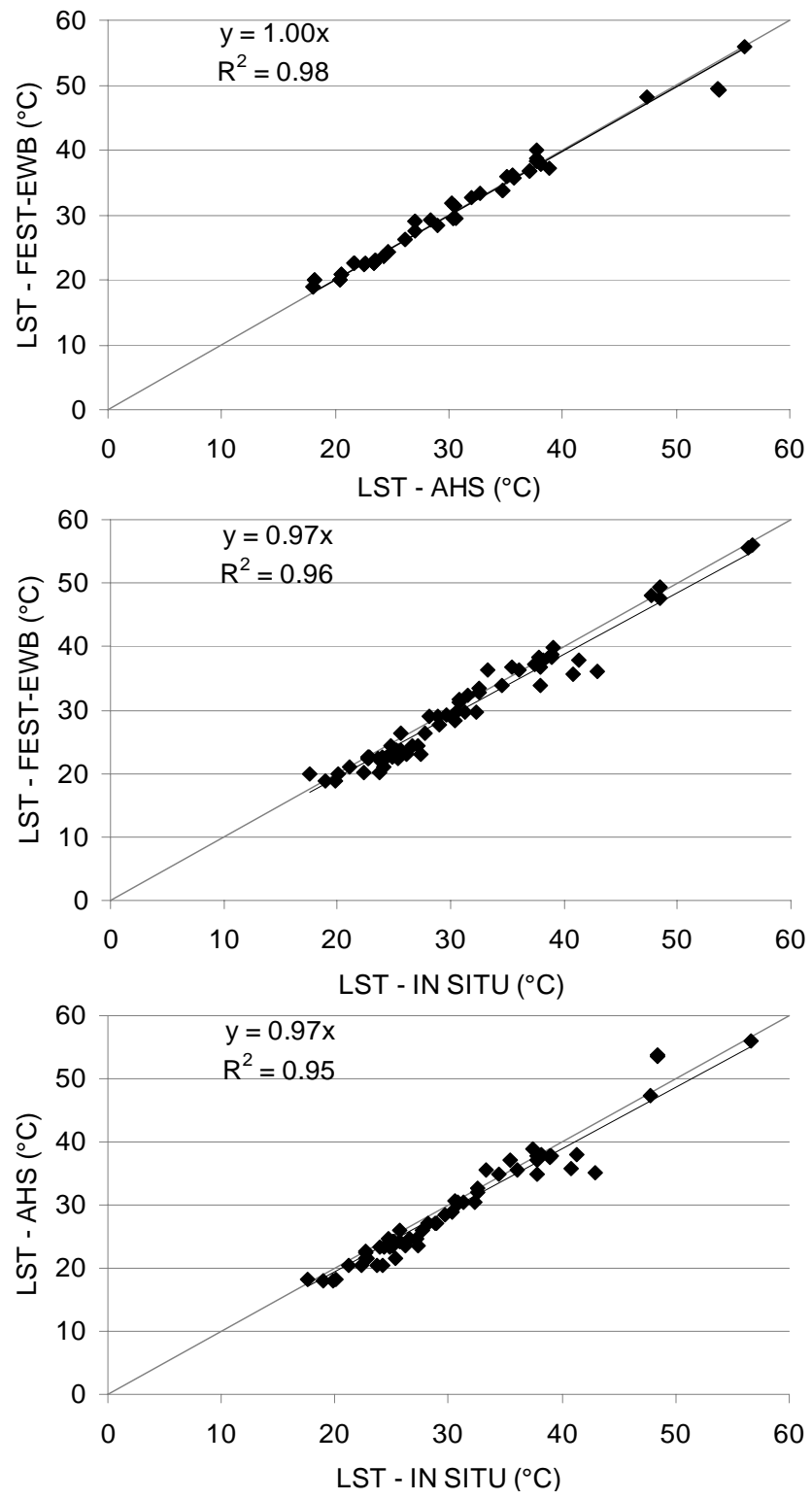

Fig. 3. Scatter plots between LST from AHS, FEST-EWB and in situ measurements.

\subsection{Daytime hours}

The comparison of daytime maps for 13 July at 13:45 (Fig. 4) shows a good behaviour of modelled RET in representing the spatial heterogeneity of LST image from AHS with similar mean and standard deviation values (Table 4). These simple statistics are also confirmed from the histograms that show a quasi bimodal distribution due to the distinction between crops and bare soil (Fig. 4) (McCabe and Wood, 2006). Moreover AHS and FEST-EWB histograms show at lower temperatures, between 25 and $45^{\circ} \mathrm{C}$, a lot of classes due to the presence in the fields of crops at different growth stages and of different soil moisture conditions. 
Table 3. Mean difference, standard deviation and RMSE between LST-AHS and FEST-EWB.

\begin{tabular}{lrrll}
\hline $\begin{array}{l}\text { Date } \\
\text { (yymmdd) }\end{array}$ & Time & $\begin{array}{r}\text { Mean LST }\left({ }^{\circ} \mathrm{C}\right) \\
\text { (FEST_EWB-AHS) }\end{array}$ & $\begin{array}{l}\text { Standard } \\
\text { deviation }\left({ }^{\circ} \mathrm{C}\right)\end{array}$ & RMSE $\left({ }^{\circ} \mathrm{C}\right)$ \\
\hline $\begin{array}{l}\text { Total mean } \\
\text { Diurnal mean }\end{array}$ & - & -0.33 & 1.26 & 2.46 \\
Nocturnal mean & - & -0.15 & 1.38 & 2.37 \\
\hline 050712 & $13: 56$ & -1.21 & 0.69 & 2.91 \\
050712 & $14: 21$ & 0.88 & 1.62 & 2.72 \\
050712 & $00: 07$ & -0.45 & 1.58 & 2.56 \\
050712 & $00: 32$ & -1.24 & 0.73 & 3.36 \\
050713 & $9: 52$ & -1.19 & 0.65 & 2.46 \\
050713 & $10: 15$ & -1.26 & 0.79 & 3.23 \\
050713 & $13: 46$ & -0.09 & 0.9 & 1.31 \\
050713 & $14: 01$ & 0.62 & 1.83 & 2.69 \\
050714 & $10: 03$ & 0.45 & 1.9 & 2.6 \\
050714 & $10: 23$ & -0.3 & 0.79 & 1.35 \\
050714 & $14: 06$ & 0.13 & 0.85 & 1.39 \\
050714 & $14: 25$ & -0.71 & 1.69 & 2.7 \\
\hline
\end{tabular}

Table 4. Mean and standard deviation for the comparison between LST from MODIS, AHS and FEST-EWB.

\begin{tabular}{lllrr}
\hline & AHS & $\begin{array}{l}\text { FEST-EWB } \\
(10 \mathrm{~m})\end{array}$ & $\begin{array}{r}\text { FEST-EWB } \\
(1000 \mathrm{~m})\end{array}$ & MODIS \\
\hline 13 July at 00:10 & & & & \\
\hline Pixel n & 857229 & 38298 & 6 & 3 \\
Mean LST $\left({ }^{\circ} \mathrm{C}\right)$ & 21 & 19.9 & 20.1 & 19.7 \\
St. Dev. $\left({ }^{\circ} \mathrm{C}\right)$ & 1.4 & 0.9 & 0.7 & 0.1 \\
\hline 13 July at 13:46 & & & & \\
\hline Pixel n & & & 6 & 5 \\
Mean LST $\left({ }^{\circ} \mathrm{C}\right)$ & 42 & 42.9 & 43.8 & 41.3 \\
St. Dev. $\left({ }^{\circ} \mathrm{C}\right)$ & 8.8 & 9.6 & 3 & 1.2 \\
\hline
\end{tabular}

Instead if MODIS LST coarser image $(1000 \mathrm{~m})$ and RET at the spatial resolution of $1000 \mathrm{~m}$ are considered, in Fig. 4 it is clearly visible that they do not capture the strong spatial heterogeneity of LST from AHS, but only the mean value (Table 4). The lower spatial accuracy of MODIS and FESTEWB $(1000 \mathrm{~m})$ is also evident in the frequency distribution graphs (Fig. 4).

\subsection{Nocturnal hours}

The night images of 13 July at 00:10 are selected for the comparison and a strong homogeneity in land surface temperature distribution for all the three different spatial resolutions is shown (Fig. 5). In fact the difference between crops and bare soil is no longer visible, as well as the different stages of vegetation growth and the different soil moisture conditions. In particular a good behaviour of FEST-EWB model in representing LST image from AHS is shown with similar statistic values (Table 4). Moreover, during night time, also MODIS and FEST-EWB $(1000 \mathrm{~m})$ coarser images can represent this homogeneous thermodynamic characteristic of the area as well as the high resolution images (Fig. 5). In fact the four images have a similar mean value, ranging from $19.7{ }^{\circ} \mathrm{C}$ to $21^{\circ} \mathrm{C}$, and small standard deviations (from $0.1^{\circ} \mathrm{C}$ to $1.4^{\circ} \mathrm{C}$ ) (Table 4 ).

Moreover, this homogeneity is also confirmed from the frequency distribution graphs (Fig. 5) where, as expected, mean values of the three images are in the same class and a low variance is found.

\section{LST aggregation effect and its spatial correlation}

Modelled RET and LST from AHS have been aggregated at subsequent increasing spatial resolution $(50 \mathrm{~m}, 100 \mathrm{~m}, 500 \mathrm{~m}$ and $1000 \mathrm{~m}$ ), keeping the same number of pixels of the $10 \mathrm{~m}$ image (Fig. 6), to understand their spatial variability and the aggregation effect on some statistical parameters, such as the mean, the variance and the variation coefficient $(\mathrm{CV})$.

An interesting aspect of the spatial variability of land surface temperature at different spatial scales is the analysis of the mutual relationship between its values in each pixel. These relationships between different LST pixel values at a define distance have been analysed with the spatial autocorrelation function $(\mathrm{AC})$ :

$\operatorname{AC}\left(d_{1,2}\right)=\frac{E\left\{\left[L S T\left(X_{1}\right)-\mu\right] \cdot\left[L S T\left(X_{2}\right)-\mu\right]\right\}}{\sigma^{2}}$ 

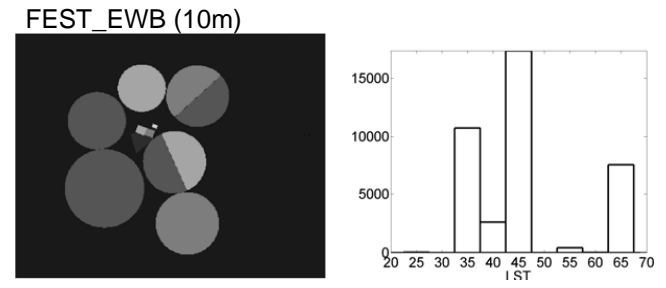

AHS (2m)

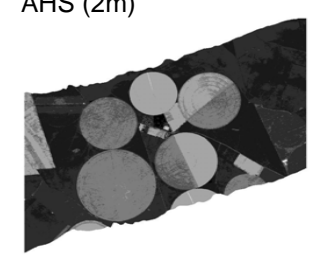

MODIS (1000m)

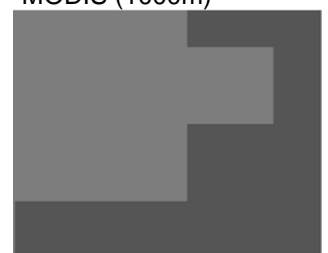

FEST_EWB (1000m)

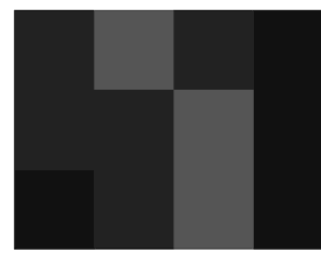

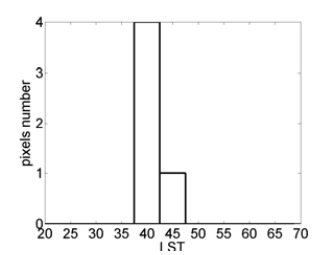

$41^{\circ} \mathrm{C}$
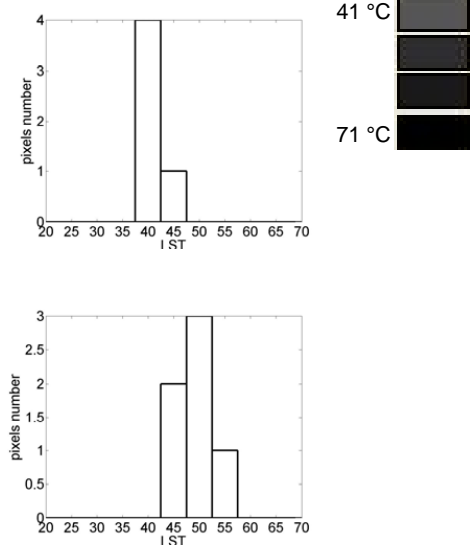

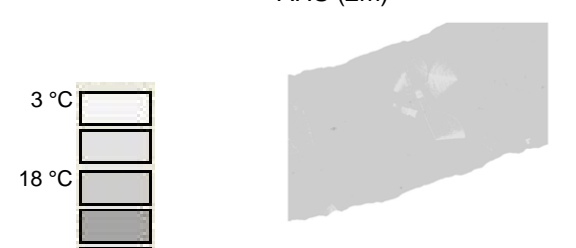

MODIS (1000m)

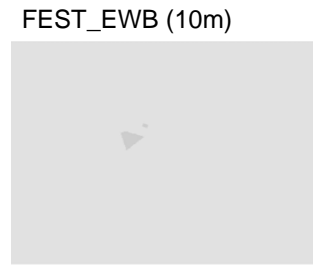

AHS (2m)

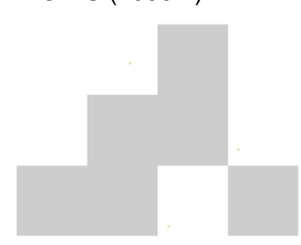

FEST_EWB (1000m)
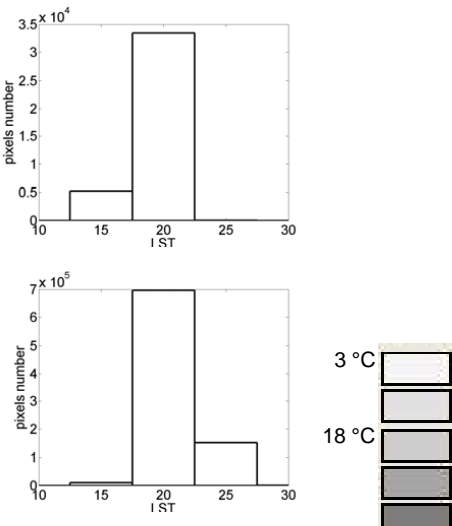

$41^{\circ} \mathrm{C}$
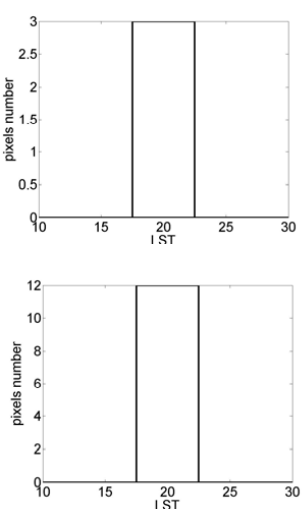

Fig. 4. Frequency distribution for LST from AHS, FEST-EWB (10 m-1000 $\mathrm{m}$ ) and MODIS for 13 July at 13:45.

where $\mu$ is the mean and $\sigma^{2}$ is the variance of LST in stationary hypothesis, so that a stochastic process, whose joint probability distribution does not change in time or space, is considered. $x_{1}$ and $x_{2}$ are the generic positions at a fixed distance $d$. The autocorrelation function has been studied under isotropy hypothesis so that $d$ is a function only of the distance between two points and not of the direction.

LST map of 13 July 2005 at 13:46 was selected for this analysis. In Fig. $7 \mathrm{AC}$ values are reported as a function of distance for RET and LST from AHS at $10 \mathrm{~m}$ spatial resolution. The two autocorrelation functions are similar till $150 \mathrm{~m}$ of distance, showing the good behaviour of the model in representing the observed data at high spatial resolution. Moreover, as expected, $\mathrm{AC}$ values are equal to 1 at a $0 \mathrm{~m}$ distance and decreases till values near zero as the distance between the two pixels increases. The simulation has been stopped at $560 \mathrm{~m}$ distance, because higher distances are of lower interest due to the scarce number of couples of LST points. This result implies that the presence of bare soil or of different vegetation types at different growth stages and the different soil moisture conditions are responsible of the relationship between pixels at different land surface temperatures.

Fig. 5. Frequency distribution for LST from AHS, FEST-EWB $(10 \mathrm{~m}-1000 \mathrm{~m})$ and MODIS for 13 July at 00:10.

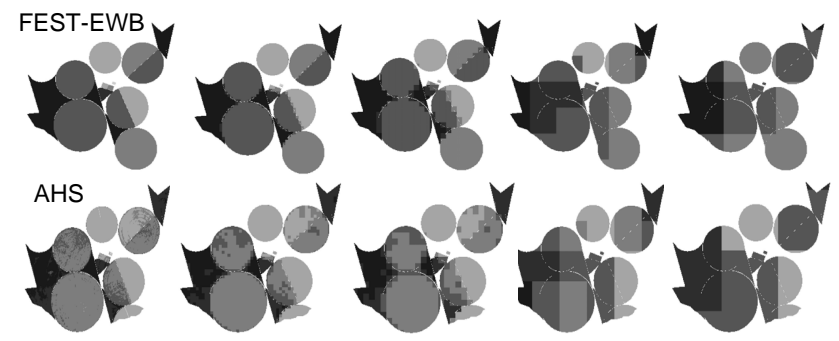

Fig. 6. RET from FEST-EWB (on top) and LST from AHS (below) at the different spatial resolutions of $10 \mathrm{~m}, 50 \mathrm{~m}, 100 \mathrm{~m}, 500 \mathrm{~m}$ and $1000 \mathrm{~m}$.

The autocorrelation functions are also reported for the different aggregation scales for FEST-EWB and AHS and similar results are obtained. Moreover, AC values decrease with the distance but more slowly at a lower spatial resolution, due to the increasing homogeneity of the area (Fig. 8).

The autocorrelation functions for LST from MODIS and FEST-EWB at $1000 \mathrm{~m}$ are compared to the AC functions of the aggregated images at $1000 \mathrm{~m}$ from AHS and FEST-EWB (Fig. 9). The two aggregated images, with similar behaviour, have higher autocorrelation values than LST aggregated at $1000 \mathrm{~m}$. 


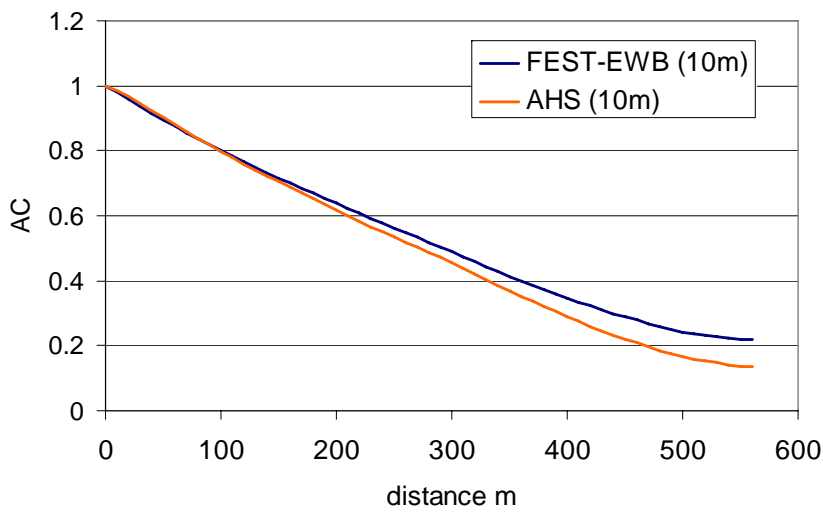

Fig. 7. Autocorrelation function for LST maps from FEST-EWB and AHS for 13 July 2005 at 13:46 at $10 \mathrm{~m}$ of spatial resolution.
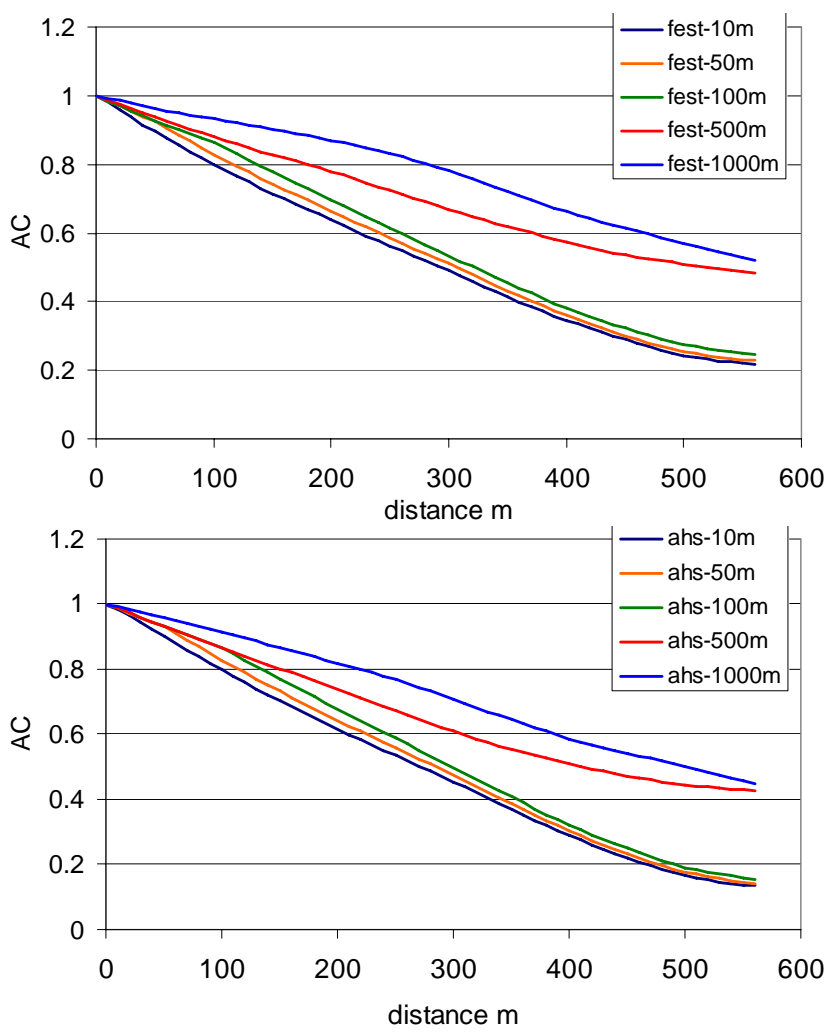

Fig. 8. Comparison between autocorrelation functions for LST maps from FEST-EWB model at different spatial resolution of $10 \mathrm{~m}$, $50 \mathrm{~m}, 100 \mathrm{~m}, 500 \mathrm{~m}$ and $1000 \mathrm{~m}$.

The more common statistical parameters have also been analysed and, as expected, variances and CVs decrease with increasing the aggregation area, while the mean values remain almost constant (Rodriguez-Iturbe et al., 1995) (Fig. 10). In particular the variances can be interpolated as two power law functions and the passage between them seems to be located at the autocorrelation distance, equal about to $500 \mathrm{~m}$. This means that with the increase of the ag-

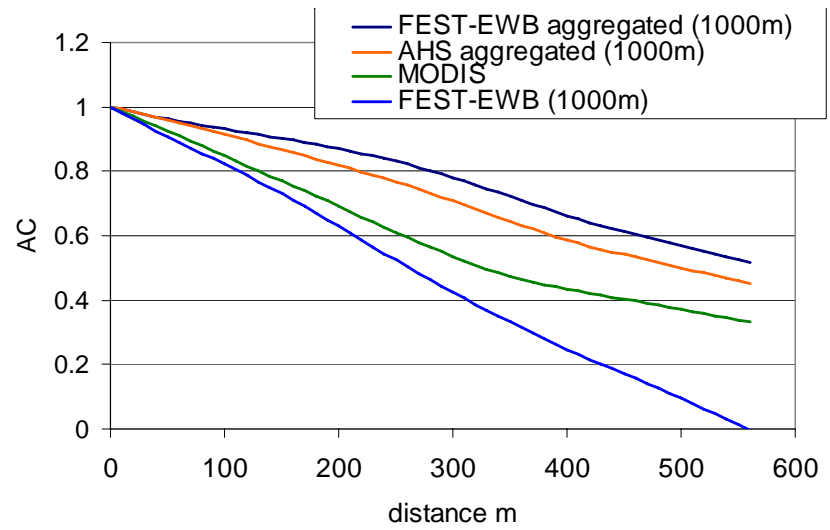

Fig. 9. Comparison between autocorrelation functions of LST from MODIS, FEST-EWB and AHS at the spatial resolution of $1000 \mathrm{~m}$.

gregation area further than the autocorrelation distance, pixels with higher difference of LST are included into the aggregation area. AHS and FEST-EWB aggregated images seem to have a similar behaviour during this aggregation process; instead, if the statistical parameters for LST from MODIS and FEST-EWB simulated at $1000 \mathrm{~m}$ are considered, lower values of variance and variation coefficient in comparison to the ones of the aggregated FEST-EWB and AHS at $1000 \mathrm{~m}$ are found.

\subsection{LST scale of fluctuation}

In the analysis of signal, the concept of scale of fluctuation (VanMarcke, 1983) can be used as a significant parameter to understand the spatial variability of a generic process. This theory will be used to characterize land surface temperature from FEST-EWB and from AHS.

In particular for a stationary process, the scale of fluctuation can be defined as:

$\alpha=\lim _{A \longrightarrow \infty} \Gamma(A) \cdot A$

where $\Gamma(A)=\sigma_{A}^{2} / \sigma^{2}, A$ is the aggregation area and $\sigma_{A}^{2}$ is the variance of the aggregated process.

$\Gamma(A)$ is linked to the correlation function as:

$\Gamma(A)=\frac{1}{L_{1} L_{2}} \int_{-L 2}^{L 1} \int_{-L 1}^{L 2}\left(1-\frac{\left|d_{1}\right|}{L_{1}}\right)\left(1-\frac{\left|d_{2}\right|}{L_{2}}\right) \mathrm{AC}\left(d_{1,2}\right) \cdot d_{1} \cdot d_{2}$

So the scale of fluctuation can also be expressed as function of the correlation function, as the volume below the AC function:

$\alpha=\int_{-L 2}^{L 1} \int_{-L 1}^{L 2} \mathrm{AC}\left(d_{1,2}\right) \cdot d_{1} \cdot d_{2}$

if this hypothesis is verified:

$\lim \operatorname{AC}\left(d_{1,2}\right)=0$ 


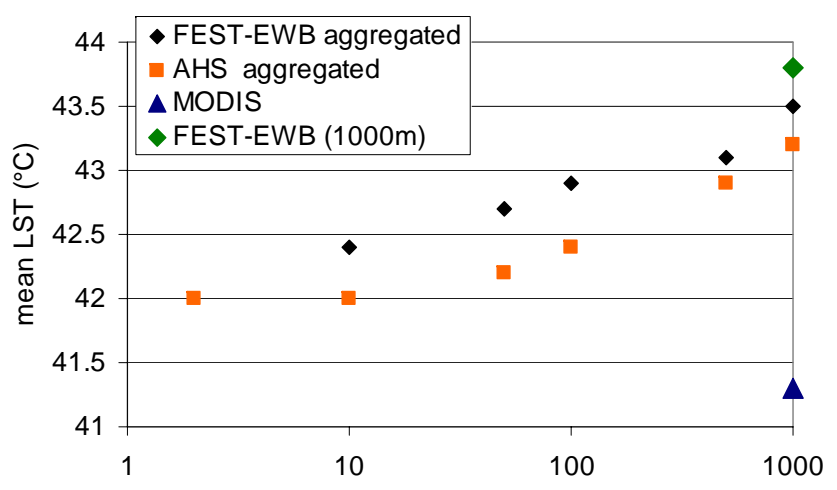

$\log ($ pixel resolution $(\mathrm{m}))$
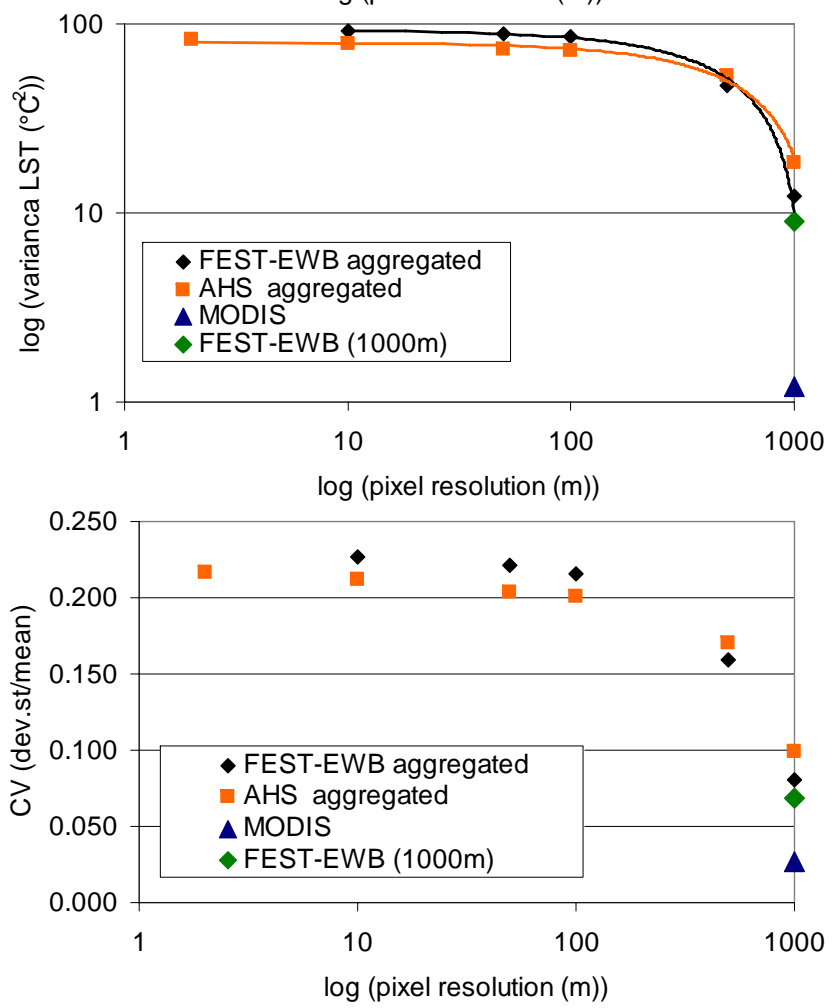

Fig. 10. Comparison between the mean, the standard deviation and the variation coefficient for LST from AHS and FEST-EWB at different spatial resolution $(10 \mathrm{~m}, 50 \mathrm{~m}, 100 \mathrm{~m}, 500 \mathrm{~m}$ and $1000 \mathrm{~m})$ and LST from MODIS and FEST-EWB simulated at $1000 \mathrm{~m}$.

Due to the fact that at different aggregation level an autocorrelation function exists (Fig. 8), a scale function can be defined for each spatial resolution, but only starting from the highest resolution to the lowest one and not viceversa. In this way $\alpha$ can be used as a superior limit above which continuing the aggregation process, the information about variance are lost.

The scale of fluctuation can be also written in the frequency field:

$\alpha=4 \pi^{2} \cdot g(0,0)$

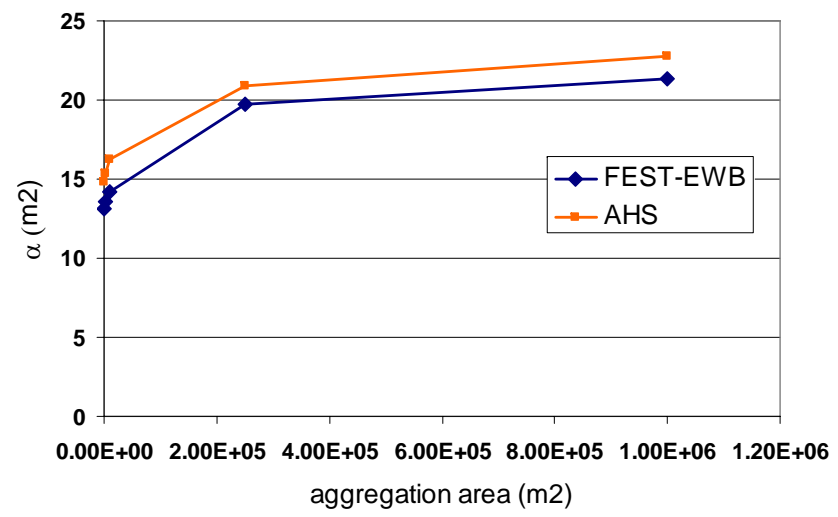

Fig. 11. Scales of fluctuation of LST for different aggregation areas.

where $g\left(\omega_{1} \omega_{2}\right)$ is the spectral density function $G\left(\omega_{1} \omega_{2}\right)$ divided by the variance at the scale of the process and $\omega_{1} \omega_{2}$ are the frequencies in the direction $d_{1}$ and $d_{2}$. The spectral density function is the Fourier transform of the autocorrelation AC function.

In Fig. 11 the scales of fluctuation for RET and LST from AHS are reported and $\alpha$ grows with the growing of the aggregation area very quickly, but for $A>>\alpha$ the scales of fluctuation remain constant. This constant value, from the definition of scale of fluctuation, is the estimate of the area above which LST variance becomes insignificant for the process. These results confirm the previous ones, showing that the area of significance of this hydrological variable is equal to the area defined from the autocorrelation function.

From these analyses, for a process at higher aggregation, the variance tends to zero while the scale of fluctuation is higher. So that the product between the scale of fluctuation and the relative variance is constant:

$\alpha_{a} \cdot \sigma_{a}^{2}=\alpha_{A} \cdot \sigma_{A}^{2}$

These concepts can also be related to the hydrological modelling observing that a lumped model has obviously a bigger level of indetermination than a distributed model.

\section{Conclusions}

The representativeness of LST for a distributed hydrological water balance model, FEST-EWB, has been analysed. The hydrological model performed well for the whole period of observation and was able to accurately predict energy fluxes measured at an eddy covariance station and land surface temperature spatial and temporal distribution in comparison to in situ thermal infrared radiometric measurements, high and low spatial resolution remote sensing images.

Diurnal AHS images of LST at high spatial resolution, as well as simulated RET from hydrological model, are able to correctly reprodcue the strong spatial variability of the area 
with high standard deviation. On the contrary, MODIS images, due to the low spatial resolution, are able to detect only the mean LST value. Instead during night time, coarser images spatial resolution seems to be sufficient to represent the lower LST spatial variability of the fields showing the same statistics of higher resolution images. This observation highlights the role of operative satellite that can be used in an assimilation process into hydrological energy balance models.

Moreover AHS and FEST-EWB aggregated images seem to have a similar behaviour during the aggregation process showing similar values of variance, $\mathrm{CV}$ and autocorrelation function; while the coarser LST from MODIS and FESTEWB simulated at $1000 \mathrm{~m}$ have lower values of variance and variation coefficient.

A constant value of the scale of fluctuation, above which LST variance becomes insignificant for the process, is reached and it is equal to the significant area found from the autocorrelation function.

Acknowledgements. This work was funded by MIUR in the framework of the Azioni Integrate Italia-Spagna project (prot. IT09G9BLE4) "Land Surface temperature from remote sensing for operative validation of an hydrologic energy water balance model" and of the ACQWA EU/FP7 project (grant number 212250) "Assessing Climate impacts on the Quantity and quality of WAter".

Edited by: D. F. Prieto

\section{References}

Anderson, M. C., Norman, J. M., Mecikalski, J. R., Torn, R. D., Kustas, W. P., and Basara, J. B.: A multiscale remote sensing model for disaggregating regional fluxes to micrometeorological scales, J. Hydrometeorol., 5, 343-363, 2004.

Bastiaanssen, W. G. M., Menenti, M., Feddes, R. A., and Holtslag, A. A. M.: A remote sensing surface energy balance algorithm for land (SEBAL) 1. Formulation, J. Hydrol., 212-213, 198-212, 1998.

Blöschl, G. and Sivapalan, M.: Scale issues in hydrological modelling: a review, Hydrol. Processes, 9(3-4), 251-290, 1995.

Corbari, C., Horeschi, D., Ravazzani, G., and Mancini, M.: Land surface temperature from remote sensing and energy water balance model for irrigation management, Options Méditerranéennes, A84, 223-234, 2008.

Corbari, C., Ravazzani, G., Martinelli, J., and Mancini, M.: Elevation based correction of snow coverage retrieved from satellite images to improve model calibration, Hydrol. Earth Syst. Sci., 13, 639-649, doi:10.5194/hess-13-639-2009, 2009

Corbari C.: Energy water balance and land surface temperature from satellite data for evapotranspiration control. $\mathrm{PhD}$ dissertation, Politecnico di Milano, Milan, Italy, 2010.

Dooge, J. C. I.: Looking for hydrologic laws, Water Resour. Res., 22(9) 46S-58S, 1986.

Famiglietti J. S. and Wood E. F.: Multiscale modelling of spatially variable water and energy balance processes, Water Resour. Res., 30, 3061-3078, 1994.
Giacomelli A., Bacchiega, U., Troch, P. A., and Mancini, M.: Evaluation of surface soil moisture distribution by means of SAR remote sensing techniques and conceptual hydrological modelling, J. Hydrol., 166, 445-459, 1995.

Gillespie, A., Rokugawa, S., Matsunaga, T., Cothern, J. S., Hook, S., and Kahle, A. B.: A temperature and emissivity separation algorithm for advanced spaceborne thermal emission and reflection radiometer (ASTER) images, Ieee T. Geosci. Remote, 36, 1113-1126, 1998.

Jasper, K., Gurtz, J., and Lang, H., Advanced flood forecasting in Alpine watershed by coupling meteorological and forecasts with a distributed hydrological model, J. Hydrol, 267, 40-52, 2002.

Jiménez-Muñoz, J. C. and Sobrino, J. A.: Feasibility of retrieving land surface temperature from ASTER TIR bands using two-channel algorithms: a case study of agricultural areas, Ieee Geosci. Remote S., 4(1), 60-64, 2007.

Kustas, W. P., Li, F., Jackson, T. J., Prueger, J. H., MacPherson, J. I., and Wolde, M.: Effects of remote sensing pixel resolution on modelled energy flux variability of croplands in Iowa, Remote Sens. Environ., 92(4), 535-547, 2004.

Mancini, M.: La modellazione distribuita della risposta idrologica: effetti della variabilità spaziale e della scala di rappresentazione del fenomeno dell' assorbimento. PhD dissertation, Politecnico di Milano, Milan, Italy, 1990 (in italian).

Mancini, M., Hoeben, R., and Troch, P.: Multifrequency Radar Observations of Bare Surface Soil Moisture Content: A Laboratory Experiment, Water Resour. Res., 35(6), 1827-1838, 1999.

McCabe, M. F. and Wood, E. F.: Scale influences on the remote estimation of evapotranspiration using multiple satellite sensors, Remote Sens. Environ., 105, 271-285, 2006.

Meyers T. P. and Hollinger S. E.: An assessment of storage terms in the surface energy balance of maize and soybean, Agr. Forest Meteorol., 125, 105-115, 2004.

Minacapilli, M., Agnese, C., Blanda, F., Cammalleri, C., Ciraolo, G., D’Urso, G., Iovino, M., Pumo, D., Provenzano, G., and Rallo, G.: Estimation of actual evapotranspiration of Mediterranean perennial crops by means of remote-sensing based surface energy balance models, Hydrol. Earth Syst. Sci., 13, 1061-1074, doi:10.5194/hess-13-1061-2009, 2009.

Montaldo N. and Albertson, J. D.: On The Use Of The ForceRestore SVAT Model Formulation For Stratified Soils, J. Hydrometeorol., 2(6), 571-578, 2001.

Montaldo, N., Ravazzani G., and Mancini, M.: On the prediction of the Toce alpine basin floods with distributed hydrologic models, Hydrol. Processes, 21, 608-621, 2007.

Nash J. E. and Sutcliffe J. V.: River flow forecasting through the conceptual models, Part 1: A discussion of principles, J. Hydrol., 10(3), 282-290, 1970.

Noihlan J. and Planton S.: A Simple parameterization of Land Surface Processes for Meteorological Models, Mon. Wea. Rev., 117, 536-549, 1989.

Norman, J. M., Kustas, W. P., and Humes, K. S.: Source approach for estimating soil and vegetation energy fluxes in observations of directional radiometric surface temperature, Agr. Forest Meteorol., 77, 263-293, 1995.

Rabuffetti, D., Ravazzani, G., Corbari, C., and Mancini, M.: Verification of operational Quantitative Discharge Forecast (QDF) for a regional warning system - the AMPHORE case studies in the upper Po River, Nat. Hazards Earth Syst. Sci., 8, 161-173, 
doi:10.5194/nhess-8-161-2008, 2008.

Ravazzani, G., Rabuffetti, D., Corbari, C., and Mancini, M.: Validation of FEST-WB, a continuous water balance distributed model for flood simulation, Proceedings of XXXI Italian Hydraulic and Hydraulic Construction Symposium, Perugia, Italy, 2008.

Rodriguez-Iturbe, I., Vogel, G. K., Rigon, R., Entekhabi, D., Castelli, F., and Rinaldo, A.: On the spatial organization of soil misture fields, Geophys. Res. Lett., 22(20), 2757-2760, 1995.

Schmugge T. J., Kustas W. P., and Humes K. S.: Monitoring Land Surface Fluxes Using ASTER Observations Ieee, T. Geosci. Remote, 36(5), 1998.

SEN2FLEX Final Report (Contract n ${ }^{0}: 19187 / 05 / I-E C$ 17628/03/NL/CB 17336/03/NL/CB), in: Proceedings of the SPARC, 4-5 July 2006, Enschede, ESA Publications Division, Noordwijk, The Netherlands.

Sivaplan, M. and Wood, E. F.: Spatial Heterogeneity and Scale in the Infiltration Response of Catchments Scale Problems in Hydrology: Runoff Generation and Basin Response, D. Reidel Publishing Co., Dordrecht Holland, NSF Grant No. CEE-8100491 and NASA Grant No. NAG-5/491, 81-106, 1986.

Sobrino J. A., Li, Z. L., Stoll, M. P., and Becker, F.: Improvements in the split-window technique for land surface temperature determination, Ieee T. Geosci. Remote, 32(2), 243-253, 1994.

Sobrino, J. A., Jiménez-Muñoz, J. C., Sòria, G., Gómez, M., Ortiz, A. Barella, Romaguera, M., Zaragoza, M., Julien, Y., Cuenca, J., Atitar, M., Hidalgo, V., Franch, B., Mattar, C., Ruescas, A., Morales, L., Gillespie, A., Balick, L., Su, Z., Nerry, F., Peres, L., and Libonati, R.: Thermal remote sensing in the framework of the SEN2FLEX project: field measurements, airborne data and applications, Int. J. Remote Sens., 29(17), 4961-4991, 2008.

Soria, G. and Sobrino, J. A.: ENVISAT/AATSR derived land surface temperature over a heterogeneous region, Remote Sens. Environ., 111, 409-422, 2007.
Su, Z., Pelgrum, H., and Menenti, M.: Aggregation effects of surface heterogeneity in land surface processes, Hydrol. Earth Syst. Sci., 3, 549-563, doi:10.5194/hess-3-549-1999, 1999.

Su, Z.: The Surface Energy Balance System (SEBS) for estimation of turbulent heat fluxes, Hydrol. Earth Syst. Sci., 6, 85-100, doi:10.5194/hess-6-85-2002, 2002.

Su, Z., Timmermans, W. J., Gieske, A. S. M., Jia, L., Elbers, J. A., Olioso, A., Timmermans, J., van der Velde, R., Jin, X., van der Kwast, H., Nerry, F., Sabol, D., Sobrinos, J. A., Moreno, J., and Bianchi, R.: Quantification of land atmosphere exchanges of water, energy and carbon dioxide in space and time over the heterogeneous Barrax site, Int. J. Remote Sens., 29, 17-18, 5215-5235, 2008.

Troch, P. A., Mancini, M., Paniconi, C., and Wood, E. F.: Evaluation of a Distributed Catchment Scale Water Balance Model, Water Resour. Res., 29(6), 1805-1817, 1993.

VanMarcke, E.: Random Fields: Analysis and Synthesis. The MIT press Cambridge Massachusetts, London, England, 1983.

Wilson, K., Goldstein, A., Falge, E., Aubinet, M., Baldocchi, D., Berbigier, P., Bernhofer., C., Ceulemans, R., Dolman, H., Field, C., Grelle, A., Ibrom, A., Law, B. E., Kowalski, A., Meyers, T., Moncrieff, J., Monson, R., Oechel, W., Tenhunen, J., Valentini, R., and Verma, S.: Energy balance closure at FLUXNET sites, Agr. Forest Meteorol., 113, 223-243, 2002.

Wood, E. F., Sivapalan, M., Beven, K., and Band, L.: Effects of spatial variability and scale with implications to hydrologic modelling, J. Hydrol., 102(1-4), 29-47, 1988.

Wood, E. F.: Scaling soil moisture and evapotranspiration in runoff models, Adv. Water Resour., 17, 1-2, 1994.

Wood, E. F.: Scale analyses for land-surface hydrology, edited by: Sposito, G., Scale dependence and scale invariance in hydrology, Cambridge, Cambrdige university press, 1-29, 1998 